ISSN: 2664-8148 (Online)
Liberal Arts and Social Sciences
International Journal (LASSIJ)
https://doi.org/10.47264/idea.lassij/ 2.2 .1
Vol. 2, No. 2, (July-December) 2018, 1-9
https://www.ideapublishers.org/lassij

\title{
Highlighting the Undemocratic Hegemony of Totalitarian Regime: An Analysis of Bisma's The Queue
}

\author{
Muhammad Arif $^{1 *}$, Humaira Ahmed ${ }^{1}$ and Bakht Rahman ${ }^{2}$
}

1. Department of English Language and Literature, National University of Modern Languages (NUML), Islamabad, Pakistan.

2. Department of English Language and Literature, Women University Swabi, Swabi, Pakistan.

\begin{abstract}
The study highlights elements of totalitarian regime in the light of the pattern given by Hanna Arendt in her book Origin of Totalitarianism. The authorities of such regimes prove to be despotic, centralized, horrible, and non-democratic. They use different techniques such as tyrannical exertions, oppression by the state, fright and trepidation, constant war on purpose, censorship of media and demand of unquestionable obedience from the masses. The research article has taken into consideration The Queue by Bisma Abdul Aziz. There is a consistent approach on the part of the ruler to set up and sustain the absolute government. It projects the desperate struggle of the regime to impose authority on the masses and signifies that any possible revolt is stricken hard as it may prove to be a threat to the regime. The study contextualizes the current political upheaval across the globe since on the one hand, there are frequent efforts to develop the democratic norms across the world while on another hand, there are countries which smash these norms just for the sake of attaining the power. The article works on the basic question that how the selected text of fiction portrays the tyrannical exertions by the omnipotent authority for the accomplishment of its ends? The aims of the study are to highlight these horrendous efforts of the authority in the selected text and to highlight its undemocratic practices.
\end{abstract}

Keywords: Despotism, Hegemony, Totalitarianism, Political Upheaval, Undemocratic Regimes, Authoritarian Regimes,

\section{Introduction}

The scholarship highlights the elements of totalitarianism in the selected text. It looks for the unjustified techniques used by the absolute authority to sustain the governments. The issue has been under discussion across the century and huge amount of scholarly works have been produced to erode the curse of centrality of the authority across the globe. The efforts prove to be nullifying since no considerable amount of change has been brought. The 2oth century has faced such political upheaval which is continued to the current days. The chaos and uncertainty in the current decade are primarily because of such undemocratic norms which are prevailing in the world. The uncertainty in the century has led to a disturb state of mind and has made the life a non-sensical activity. The article has taken into consideration the fictional text The Queue 
by Abdullah Aziz who is an Egyptian writer. The setting of the novel is a state where an unknown authority under the pen name Gate comes into existence overnight and prevails over everything. The masses in the state are in the fix since they do not understand the situation across the country. The whole political system is chaotic and there is no systematic approach towards the affairs of the state. The sole aim of the state and the authority is mutilated, since the authority in power makes every effort to impose the authority, while the masses are highly suppressed and marginalized by the state.

The twentieth century flooded with both factual and fictional works which have portrayed the political upheaval across the century. The Authority in power has always tried to suppress the masses and used various systematic ways to stop any kind of revolt. These techniques vary in range and shape, for instance; the use of technology, use of force and coercion and in certain cases might be the death punishment. Such kind of punishment is given mostly because of the revolt against the authority. Those who are stubborn against the authority becomes the epicentre of the atrocious tendencies of the government. Such tendencies of the regime prove to be highly dictatorial, sever and atrocious against the average person. One can see instances across the history where majority of the time an authority comes over night prior to any democratic process and turns out to be highly despotic. Such regimes have always denied the very definition of an organized society. The authority in power in such cases is determined to stop any kind of revolt and is obsessed with the impositions of its regulations. In certain cases, even the authority manipulates a single incident which leads to a series of undemocratic practices. In another case a foreign power may penetrate the state and control the affairs of the state overnight and turn out to be despotic and undemocratic eventually. Resultantly, in either of the above case the state is occupied by an absolutist.

An analysis of such governments shows the dictatorial tendencies of the authority which treats the masses in an unfair and undemocratic way under the umbrella term of totalitarianism. Secondly, one can very clearly see the desperate efforts of these regimes which become a source of fear for the masses and make their lives more than a burden for them. Such days of despotism make the daily life affairs a forbidden fruit for them. Thus, the social and political situation of such countries becomes unstable and totally nullifies the very definition of democracy (Arif et al., 2018). So, the basic question which has been raised is to find these horrendous efforts. The article also highlights marginalization of the masses and the despotism of these regimes as depicted in the selected text.

\subsection{Context of the Problem}

Aziz' The Queue depicts the political chaos in a Middle Eastern state which is oppressed by centralized authority under the pen name, the Gate. The study is born out of the curiosity to give a far reaching analysis of the text and to project the despotism of the totalitarian regime as depicted by the author and to highlight that is there any possibility on the part of the masses to resist the authority in power. The rationale of this research is to fill the gap by giving a comprehensive understanding of the prevailing political situation and highlighting totalitarianism in the state.

\subsection{Situatedness of the Research}

The research has highlighted the political upheaval in the selected work and the implications of the findings can be extended to the geo-political instability in the Asian countries. For 
instance, in the last decades USSR worked as a totalitarian regime and played a havoc in the central Asian states and currently, the role of global superpower is no more different from USSR. In the context, Pakistan is also supposed to be conscious about the political developments in the region. The research work gives an insight to be alert about those efforts on the part of such regimes and safeguard her autonomy and prosperity.

\section{Reviews on The Queue}

Melville housing publishers says that the novel takes us to unnamed but familiar land where a failed coup power is determined to impose the authority under the pen name the Gate. People who required any kind of document must seek its permission. They must wait till they get the permission. It depicts a dystopian society though in the fiction but can be categorized as the factual world. There is a sense of Orwellian double think in the novel. His colleague Amani tries to convince him that the bullet in his body was a fake one, but Aziz says that he was not convinced by the fact and his body was bleeding. The novel draws common grounds with the other renowned works like Kafka's The Trial, Huxley's Brave New World and Orwell's 1984. Machado writes in his book review of the novel that The Queue is new in the totalitarian absurdity. The helpless and hopeless citizens struggle against the steadfast government. The novel also gives glimpses of the anxiety and unrest brought by Arab Springs in real life. Besides these, one of the ultimate aspects of the novel which makes it much critical is, authoritarianism. The presence of such absolute authorities leaves a question for discussion.

Absolute governments have been seen across the last few decades. It got its momentum during and before the world wars. Hanna Arendt (1951) in the first part of her book Origin of Totalitarianism refers to a quotation by Roger Martin who says, "This is a remarkable century which opened with the revolution and ended with the Affaire! Perhaps it will be called the century of rubbish." The above reference refers to the political upheaval followed by the wars and chaotic social and political situation across the century. A huge amount of factual as well as fictional scholarships are available which have appreciated as well strongly condemned these regimes, primarily depending on the school of thought. Historical figures like Stalin, Linin, Mussolini, and Hitler all tried to maintain such despotic regimes. Arendt's Origin of Totalitarianism has distinguished between such regimes of the past and the current times. In the first chapter of the book named Anti-Semitism, she says, "A fundamental difference between modern dictatorships and all other tyrannies of the past is that terror is no longer used as a means to exterminate and frighten opponents, but as an instrument to rule masses of people who are perfectly obedient" (p. 6). The aim and purpose of the government had been different. Historically, it aimed to exterminate the opponent while now-a-days it works on subjugation of the masses. They are completely devoid of their basic human rights. The totalitarian acts accordingly to his logic freely submitting to his function as she further says, "the totalitarian ruler feels that only one man is required and that all other persons, all other minds as well as wills, are strictly superfluous" (p. 346). Such kind of regimes bring confinements to the citizens and their mind and abilities are aborted. Thus, the transformation of any ideology into a fullfledged totalitarian ideology is a crucial prerequisite of the totalitarian ruler.

To formulate a sound footage to the research, the researcher has referred to the historical figures from the discipline. In this context, rulers like Stalin, Hitler and Mussolini are worth mentioning who adopted such tyrannical policies. Stalinism was an ideology adopted by Stalin in Russia. Sheila Fitzpatrick in her book Everyday Stalinism (2000) says, “...the state was a central and ubiquitous presence" (Fitzpatrick, 2000, p. 3). She is of the opinion that life under 
Stalinism was not a normal life as she says, "But the life these ordinary people lived was not, in their own understanding and probably ours, a normal life" (p. 1). This clearly shows the centralization of the state's ideology in one hand and hence, an average person was not able to understand the situation prevailed in the country. The case of Nazism is also not much different. Bendersky in his book A concise History of Nazi Germany (2014) says that the Nazi's desire was to transform Germany into a homogeneous racial community and he further says, "A society in which the party and its ideology would permeate every aspect of public and private life" (p. 99). Similarly, the epicentre of fascism was also the exercise of omnipotent authority. The above-mentioned examples give a theoretical model to the research work and give an analysis of the research works available in the area. Across the history such regimes share the common characteristics like despotism and centralization of power.

\section{Textual Analysis as Methodology}

The research is eclectic in nature. It is reflective/reflexive in nature. It is based on the qualitative approach of the analysis of the data. As Mats Alvesson and Kaj Skoldberg in the foreword of their book projects that qualitative analysis is based on personal interpretation. The researcher uses the same approach as no sizeable analysis of my primary texts is available (Alvesson \& Skoldberg 2000, p. vii). So in the light of the opinion of these two writers I have given mostly my own interpretation but in order to avoid the centrality of my thoughts I have taken into account the ideas, opinions and the researches of the other scholarly works and projects to reach my conclusion. The current study highlights the elements of totalitarian regime in the light of the pattern given by Hanna Arendt in her book Origin of Totalitarianism. The authorities in case of such regimes prove to be despotic, centralized, horrible, and non-democratic.

\section{Discussion and Findings}

\subsection{Tyrannical Exertions in the Selected Narratives}

Aziz's The Queue highlights the tyrannical exertions in the selected text. The whole novel revolves around the central incident named, "The Disgraceful Event." The political situation in the state is highly disturbed. The necessities of the life have become a forbidden fruit for the messes. They are supposed to seek permission of the authority even for the daily life affairs which is named as Gate as the speaker says, "Gate that increasingly began to regulate procedures, imposing rules and regulations necessary to set various affairs in motion" (p. 20). Everyone is to take permission of the Gate and to stand in a queue in front of a building which is hard to understand for them. The situation in the queue becomes worse as it does not open, and the number of the individuals' increases with every passing day. The life becomes terrible since they do not understand the situation around them.

\subsection{Oppression by the State}

The authority proves to be very oppressive and the range of oppression very in rang. The regime uses every technique that has been used in the past decades. For instance, the protagonist of the novel named Yahya is shot in the Disgraceful Event and he is supposed to seek the permission of the Gate. The doctor in the hospital is in face to face with a situation where he is to follow the instructions of the state or let the patient die. Arendt's Origin of Totalitarianism as earlier highlighted that the purpose of modern dictatorship is not elimination rather, it demands an unquestionable obedience from the masses and the same thing can be seen in the text (p. 6). In 
this context the opinion of Magaloni and Wallace is worth-mentioning who say in the dissertation titled Citizen Loyalty, Mass Protest and Authoritarian Survival that, "Citizen Loyalty is instrumental for dictatorial survival for various reasons" (Magaloni \& Wallace, 2008 , p. 1). The statement clearly shows that the modern absolute regimes does not aim to exterminate the masses, rather, they need an unquestionable obedience and the same thing can be seen in the selected text. Aziz in the annotation of his novel says, "The Queue describes the sinister nature of authoritarianism" (p. 1). In the next sentence he elaborates that the dictators manipulate the situation and mutilates the information to use them for their own purpose. Thus, it projects the nature of the absolute government.

Aziz highlights that the citizens did not have the courage to ask any question neither they were in a position to understand the political scenario of the time, as the narrator says, "No questions, no problems" (p. 8). This clearly shows that the masses were highly terrified. At another occasion he says, "In recent months the question 'Who did you pick?' had spread like the plague" (p. 11). Such despotic tendencies were aimed to bring homogeneity in the state. In this context, Bendersky in his book A concise History of Nazi Germany (2014) says that the Nazi's desire was to transform Germany into a homogeneous racial community and he further says, "A society in which the party and its ideology would permeate every aspect of public and private life" (p. 99). On can very clearly find a continuity in the approach of the despotic rulers across the time. The faces, time and the geography may change but the approach is the same. The ruler in the selected fictional text is despotic, centralized, and oppressive exactly as such governments used to be in the past.

The novel projects the situation as beyond the understanding of an average person. Sheila Fitzpatrick in her book Everyday Stalinism (2000) says, "But the life these ordinary people lived was not, in their own understanding and probably ours, a normal life" (p. 1). Any state aims to bring peace, prosperity, and security to the masses. The case under consideration overviews such basic aims of the democratic state and aims to penetrate even to the private affairs of the citizens. Such political uncertainty brings a sense of insecurity in the state. After the Disgraceful Event Amani recalls the shot of Yahya and the narrator is of the opinion that even he did not know who shot him. The very presence of the Gate has become a symbol of fear for them as the narrator says, "It had no visible windows or balconies" (p. 22). One can clearly detect that there is a physical gulf between the masses and the government which is the ultimate purpose of absolute regimes.

\subsection{Emergence of Undemocratic Authority}

The Gate comes into existence overnight prior to any democratic process and it is always centralized in terms of the impositions. In this context Arendt is of the opinion that, "the totalitarian ruler feels that only one man is required and that all other persons, all other minds as well as wills, are strictly superfluous" (p. 346). This means that the masses in the state are consistently under the suppression of the authority. This can be contextualized in the selected text, the narrator says, "...the next day, people awoke, and it was simply there" (p. 20). It is not only the emergence of the Gate rather it soon starts regulating the affairs of the state as the narrator says, "Gate that increasingly began to regulate procedures, imposing rules and regulations necessary to set various affairs in motion" (p. 20). Gandhi's Political Intuitions under Dictatorship highlights the undemocratic norm in such states and is of the opinion, "This form of political regime reflects a situation in which rulers acquire power by means other than 
competitive elections" (Gandhi, 2008, p. 7). The authority in power is both undemocratic as well as an oppressive in terms of the implementations of the rules in the country which justifies the state as an autocratic country.

\subsection{Imposition of Single Ideology}

Another distinct characteristic of totalitarian regime is the imposition of singular ideology. The whole governmental machinery is unipolar and unidirectional. In this context Arendt gives a direction to such regime in the chapter Anti-Semitism and she is of the opinion that "A fundamental difference between modern dictatorships and all other tyrannies of the past is that terror is no longer used as a means to exterminate and frighten opponents, but as an instrument to rule masses of people who are perfectly obedient" (p. 6). In this context the opinion of Bendersky is worth mentioning who is of the opinion in his book A concise History of Nazi Germany (2014) that the Nazi's desire was to transform Germany into a homogeneous racial community and he further says, "A society in which the party and its ideology would permeate every aspect of public and private life" (p. 99). The narrator of the novel discusses that the Gate comes into existence over-night and he further elaborates the nature of the authority in terms of the single ideology as, "being forced to follow the strict order the Gate had imposed" (p. 8). The same idea has been extended by the selected theorist as, "...the totalitarian ruler feels that only one man is required and that all other persons, all other minds as well as wills, are strictly superfluous" (p. 346). The intensity of the ideological impositions can be gathered from the narrator's opinion as he says, "less authoritarian system" (p. 8). The statement shows that the citizens were being treated very harshly and they were looking for lenient government to help them instead of suppression.

As mentioned earlier the regime is so much strict about the imposition of the state's ideology that one can see that the masses are always marginalized. The narrator says that everyone must receive the certificate of true citizenship as he says, "Galabaya is in the queue with card in his hand, Certificate of True Citizenship" (p. 10). When the protagonist is fired in the Disgraceful Event, the situation is worst as the speaker says, "Yehya's blood had drenched the floor and the bedsheets" (p. 18). Had it been in any democratic state the situation would have been different. In this respect the laws of the state are consistently being updated. For instance, the new addition to the law is article 4(A), says that to remove the bullet form the body of any patient or any firearm projectile in any private clinic or government hospital was a criminal act, prior to the permission of the Gate. The above discussion can be elaborated in the light of the debate by Linz' Totalitarian and Authoritarian Regimes who is of the opinion that such regime is, "political systems with limited, not responsible, political pluralism, without elaborate and guiding ideology" (Linz, 2000, p. 159). So, the regime in the state under consideration is highly centralized, monolithic in approach which is against the very definition of any democratic society.

\subsection{Fear, Trepidation a Leading Practice}

Fear, trepidation and use of coercion are the primary elements of undemocratic hegemony of the authorities in power. Hannah Arendt's in the chapter Ideology and Terror: A Novel Form of Government develops the idea that the predominant element of such regimes was to carry the impositions by using coercions. Sheena Greitens, a critic adopts the approach in her book Dictators and Their Secret Police: Coercive Institutions and State Violence and she is of the opinion that the prime focus of such regime is the use of coercion. The Gate in the state make 
Quell Force and the basic aim of the force is to carry the tyrannical exertions. It beats the people and the purpose of these brutalities is discussed by the narrator as, "return people to their senses," by "beating them brutally" (p. 9). So, the sole purpose of such undemocratic tendencies is to bring homogeneity in the state.

The brutalities of the totalitarian regime do not go in vain. The aim of totalitarian regime is to make the masses passive as the narrator says, "In the end, the Gate and its guardians had prevailed" (p. 9). Such unhealthy activities on the part of the absolute authorities can be seen across the history. In this context, Bradley in his dissertation titled Saddam Hussain: Portrait of an Arab Leader (1977) refers to the totalitarian regime in Iraq under the president Saddam Husain and is of the opinion, "...his domestic use of the armed forces against the Kurds provides insights into the military's role in domestic stability" (Bradley, 1977, p. 41). Another instance, with respect to the same assumption has been discussed by Nicole Elizabeth in her dissertation Ferdinand Marcos: Apotheosis of the Philippine Historical Political Tradition that Ferdinand manipulated the ideology in order to dilute the opposition and to legitimize his undemocratic regime.

\subsection{Constant War on Purpose}

An analysis of the totalitarian regimes across the history shows that they have engaged with a constant war on a purpose (insurgency). In the context, one can take the examples of Hitler from the factual world as well as the example of Orwell's 1984 from the fictional world. Shirer in his book The Rise and Fall of the Third Reich: A History of Nazi Germany refers to the war dairy of General Franz Halder who writes that; when Hitler attacked Poland; that time, "the enemy is practically beaten." (Shirer, 1995, p. 625). Romaniuk's Becoming Hitler's Army: Nazi Killers and the Making of Genocidal warfare refers to the speech delivered by Hitler to his generals during the same attack who said, "Our strength lies in our speed and our brutality..." (Romaniuk, 2002, p. 478). Similarly, the Orwell's 1984 depicts the state, Oceania's, under constant war on a purpose. The situation in The Queue is not much different and shows that the state has made Quell Force and Deterrence force to carry a constant war like situation into the state. The narrator says that interesting thing about these wars is, "no one could tell exactly who the people involved were" (p. 47). Such kind of insurgency is carried in the state to keep the masses in a fix and run the affairs smoothly, irrespective of the interest of the masses and the state.

\subsection{Censorship of Media}

In the modern era media is considered as the $4^{\text {th }}$ pillar of the state. It fills the gap between the authority and the citizens. Any dictator proves to have a strict check on the sources of media. Day's Censorship or Freedom of Expression? discusses the espionage act of 1917, during the days of WWI and says, "The Espionage Act of 1917 prohibited the publication of information concerning the national defence" (Day, 2001). The selected text highlights that both, the print and electronic media is highly regularized by the state. The speaker says "Later, the Gate issued a decree that forbade other channels from screening any announcements other than its own" (p. 59). It is not only electronic media, rather, with respect to print media the narrator says, "...the only paper he was selling was The Truth" ${ }^{1}$ (p. 60). The examples show that the authority is very much conscious with respect to regulation of the media so that to be successful to the utmost level in imposition of the authority. 


\section{Conclusion}

The research article has highlighted the elements of totalitarian regime in the selected work. The aims of the research work are to find the horrible practices made by such regimes to sustain the absolute authority. The key elements which the research work has found are, like, centralization of authority, unquestionable obedience from the masses, constant war on purpose, censorship of media and despotism. Such regime is in desperate struggle to impose the authority since it is obsessed with the use of coercion. It denies every definition of the democratic state. There is a master-slave relation between the authority and the masses which is nothing else than the exploitation of the masses. One does not feel like in home because there is undemocratic hegemony which is the worst form the government.

\section{References}

Alvesson, M. A., \& Skoldberg (2000). Reflexive methodolgy: New vistas for qualitative research. London: Sage Publications.

Arendt, H. (1951). Origin of totaliterianism. New York: Harcourt Brace \& Company.

Arif, M., Ahmed, H., \& Rahman, B. (2018). Dismantling panopticonic regime: Study of Orwell's 1984. Liberal Arts and Social Sciences International Journal (LASSIJ), 2(1), $10-19$.

Aziz, A. B. (2016). The Queue..

Bradley, R. (1977). Saddam Hussain: Portrait of an Arab leader. Texas: Texas A\&M University. College Station.

Bendersky, J. ( 2014 ). A concise history of Nazism. United Kingdom: Rowman \& Littlefield Publishers.

Brooman, J. (1985). Hitler's Germany. New York: Longman.

Day, N. (2001). Censorship or freedom of expression? Minneapolis: MN: Lerner Publication Group. In Eagleton, T. (1983). Literary Theory: An Inroduction. London: Oxford.

Fanon, F. (2008). Black skins white masks. London: Pluto Press.

Fitzpatrick, S. (2000). Everyday Stalinism. New York: Oxford Press Univrsity.

Gandhi, J. (2008). Political institutions under Dictatorship. Cambridge: Cambridge University Press.

Griffin, G. (2005). Research method for English studies. Edinburgh: Edinburgh UP.

Hirshe, E. (1967). Valadity in interpretation. New Haven: Yale UP.

Huxley, A. (1931). Brave new world. London: Oxford University Press.

Linz, J. J. (2000). Totalitarian and authoritarian regimes. London: Lynne Rienner.

Majkowski, J. (2017). How successful was Joseph Stalin in establishing the Soviet Union as a superpower? Journal of Education Culture and Society.

Magaloni, B., \& Wallace, J. (2008). Citizen loyalty, mass protest and authoritarian survival. In Conference on Dictatorship: Their Governance and Social Consequences. Princeton University.

Nawaz, S., Rao, T., \& Afzal, F. (2005). Allegory and satire on animal form by George Orwell. International Journal of Academic Research and Reflection.

Orwell, G. (1949). 1984. New York: Oxford.

Orwell, G. (2008). Animal form. London: Panguin Publishers.

Rad, Z. (2015). George Orwell's Animal farm: From Utopia to Dystopia. Jstor.

Rick, T. (2006). Fiaso: The American military adventure in Iraq. United States: Panguin Group. 
Robert, P. (2004). The anatomy of Fascism. New York: Alfred A. Knopf.

Romanuik, S. (2002). Becoming Hitler's army: Nazi killers and the making of genocidal warfare. Harlow: Longman.

Schwandt, T. A. (1997). Qualitative inquiry: A dictionary of terms. California: Sage Publications.

Selenito, J. D. (1843). Fear and trembling. Denmark: Penguin Classic.

Shirer, W. (1995). The rise and fall of the third reich: A history of Nazi Germany. London: Folio Society.

Topham, J. (2017). Book Review: Review of George Orwell's 1984. Thought Co.

Note:

${ }^{1}$ The Truth. The only newspaper which is published. 